\title{
Electrochemical reversibility of magnesium deposition-dissolution on aluminum substrates in Grignard reagent/THF solutions
}

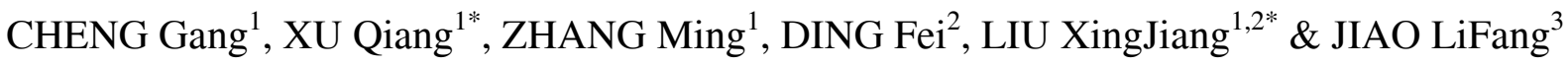 \\ ${ }^{1}$ School of Chemical Engineering and Technology, Tianjin University, Tianjin 300072, China; \\ ${ }^{2}$ National Key Laboratory of Science and Technology on Power Sources, Tianjin Institute of Power Sources, Tianjin 300384, China; \\ ${ }^{3}$ Institute of New Eenergy Material Chemistry, Key Laboratory of Advanced Energy Materials Chemistry, Ministry of Education, Nankai University, \\ Tianjin 300071, China
}

Received February 17, 2013; accepted May 20, 2013; published online July 23, 2013

\begin{abstract}
The electrochemical behavior of magnesium deposition-dissolution on scratched aluminum foils in Grignard reagent/tetrahydrofuran (THF) solutions $\left(1 \mathrm{~mol} \mathrm{~L}{ }^{-1} \mathrm{EtMgBr} / \mathrm{THF}\right)$, which is regarded as a potential electrolyte of rechargeable magnesium batteries, was studied by using various methods such as cyclic voltammetry (CV), scanning electron microscopy (SEM), X-ray diffraction (XRD) and charge-discharge (deposition-dissolution) tests. The results present that the obtained magnesium deposits do not exhibit the morphology of dendrite and the $\mathrm{Mg}-\mathrm{Al}$ alloy is not found on the surface of aluminum foils. The magnesium deposited on the aluminum substrates have excellent electrochemical cyclic performance in $1 \mathrm{~mol} \mathrm{~L}^{-1} \mathrm{EtMgBr} / \mathrm{THF}$ solution. The aluminum can be used as a candidate material of the negative current collector for rechargeable magnesium batteries.
\end{abstract}

rechargeable magnesium battery, deposition-dissolution, aluminum, dendritic morphology, cyclic performance

Citation: Cheng G, Xu Q, Zhang M, et al. Electrochemical reversibility of magnesium deposition-dissolution on aluminum substrates in Grignard reagent/THF solutions. Chin Sci Bull, 2013, 58: 3385-3389, doi: 10.1007/s11434-013-6008-7

Electrochemical energy storage devices are key components for innovative power train systems such as plug-in hybrid vehicle (PHV), fuel cell hybrid vehicle (FCHV), and electric vehicle (EV) [1,2]. Currently, Li-ion batteries have been widely used in the fields of hybrid electric vehicles (HEV) and EV due to their high energy densities. However, there are some shortcomings which have not been resolved in Li-ion batteries, such as poor safety performance and high cost $[3,4]$. Magnesium as an electrode has the advantages of high Faradic capacity, environmental acceptability, good reliability, high safety and low cost. Therefore, the rechargeable magnesium battery is considered as an ideal substitution for the Li-ion battery in the future [5,6], which is becoming an attractive power battery and developed by many international companies and research institutes [7,8].

Liebenow [9] has investigated that the reversibility of electrochemical magnesium deposition on Au and Ag sub-

*Corresponding authors (email: xuqiang_tj@163.com; xjliu@nklps.org) strates in Grignard reagent/ether solutions. The magnesium deposits on $\mathrm{Au}$ and $\mathrm{Ag}$ substrates have smooth and compact morphologies. Aurbach et al. [10-14] studied the electrochemical deposition-dissolution mechanisms of magnesium on Au substrates in different ethereal solutions of complexes of the $\mathrm{Mg}\left(\mathrm{AX}{ }_{4-n} \mathrm{R}_{n^{\prime}} \mathrm{R}_{n^{\prime \prime}}^{\prime}\right)_{2}$ type (A=Al, B; X=Cl, Br; R, R'= alkyl or aryl groups; and $\left.n^{\prime}+n^{\prime \prime}=n\right)$ by using various analytical techniques. They found that the electrolyte was a key factor on morphologies of the magnesium deposits. Nuli et al. $[15,16]$ reported that electrochemical deposition-dissolution processes of magnesium in both ionic liquid electrolytic solutions of $\mathrm{BMIMBF}_{4}$ and PP13TFSI with $1 \mathrm{~mol} \mathrm{~L}^{-1}$ $\mathrm{Mg}\left(\mathrm{CF}_{3} \mathrm{SO}_{3}\right)_{2}$ are highly reversible. Wang et al. [17] have studied the electrochemical magnesium deposition-dissolution behavior in a mixed ionic liquid of $\mathrm{BMIMBF}_{4}$ and PP13TFSI with the volume ratios of $2: 1,3: 1$, and $4: 1$ in the presence of $0.3 \mathrm{~mol} \mathrm{~L}{ }^{-1} \mathrm{Mg}\left(\mathrm{CF}_{3} \mathrm{SO}_{3}\right)$, respectively. They found that those mixed electrolyte systems were well compatible with the deposition-dissolution of magnesium 
and the reversible behavior could be maintained over 200 cycles. Gummow and He [18] have explored the morphologies and the preferred orientation of magnesium electrodeposited on stainless steel substrates by electrical pulse in $3 \mathrm{~mol} \mathrm{~L}^{-1} \mathrm{CH}_{3} \mathrm{MgCr} / \mathrm{THF}$ solution, $2 \mathrm{~mol} \mathrm{~L}^{-1} \mathrm{BuMgCr} / \mathrm{THF}$ solution and $1.45 \mathrm{~mol} \mathrm{~L}^{-1} \mathrm{BuMgCr} /$ dibutyl diglyme (DBG) solution, respectively. They discovered that the morphologies of magnesium deposits changed greatly with the composition of electrolytes and the charging current densities. Matsui [8] has studied the process of magnesium electrodeposition on a polished platinum substrate in $2 \mathrm{~mol} \mathrm{~L}^{-1}$ $\mathrm{EtMgCl} / \mathrm{THF}$ solution. They found that the overpotential of magnesium electrodeposition was proportional to the concentration of electrolytic solutions and the obtained magnesium deposits did not show a dendritic morphology. Zhao et al. [19] have investigated the reversibility of electrochemical magnesium deposition-dissolution on $\mathrm{Cu}, \mathrm{Ni}$ and $\mathrm{Al}$ substrates in $1 \mathrm{~mol} \mathrm{~L}^{-1}$ pyrrolidinyl magnesium halide/tetrahydrofuran solutions $\left(\mathrm{C}_{4} \mathrm{H}_{8} \mathrm{NMgX} / \mathrm{THF}, \mathrm{X}=\mathrm{Br}, \mathrm{Cl}\right)$, respectively. The magnesium deposition-dissolution behavior shows excellent reversible on these three types of substrates in 1 mol L ${ }^{-1} \mathrm{C}_{4} \mathrm{H}_{8} \mathrm{NMgBr} / \mathrm{THF}$ solution at 1:1 molar ratio for EtMgBr and pyrrolidine. Kakibe et al. [20] have studied the deposition-dissolution behavior of magnesium on $\mathrm{Ni}$ substrates in a ternary ionic liquid/MeMgBr/THF solution. Their experimental results show that an electrochemical reversible process of magnesium deposition-dissolution is realized in this mixed electrolytic solution. Yoshimoto et al. [21] have investigated the deposition-dissolution behavior of magnesium on the Au substrate in an electrolyte of Grignard reagent solution (EtMgBr/THF) mixed with ionic liquid (DEMETFSI). A reversible process of magnesium deposition-dissolution has been successfully achieved in this mixed electrolyte at room temperature. Kakibe et al. [22] have also studied the electrochemical behavior of magnesium deposition-dissolution on $\mathrm{Ni}$ substrates in a binary ionic liquid electrolyte containing an organo-magnesium complex $\left(\mathrm{MeMgBr} / \mathrm{THF} /\left[\mathrm{DEME}^{+}\right]\left[\mathrm{TFSI}^{-}\right]_{0.5}\left[\mathrm{FSI}^{-}\right]_{0.5}\right)$. Their experimental results show that a good reversibility for magnesium deposition-dissolution could be obtained.

Aluminum is an essential component used as the positive current collector for Li-ion batteries [23-30]. However, aluminum could not be used as the negative current collector for Li-ion batteries owing to the alloying effect of aluminum with lithium [31,32]. In this study, the electrochemical behavior of scratched aluminum foils used as the negative current collector in Grignard reagent/THF solution $\left(1 \mathrm{~mol} \mathrm{~L}^{-1} \mathrm{EtMgBr} / \mathrm{THF}\right)$ was investigated.

\section{Experimental}

The electrochemical processes of magnesium on the surface of aluminum substrates were carried out by using a three- electrode cell assembled in an argon atmosphere glove box (MIKROUNA Advanced 2440/75), in which the concentrations of water and oxygen were kept below $1 \times 10^{-6}$ at room temperature, and the Solatron SI 1287/1260 electrochemical workstation was applied to collect the electrochemical data. The working electrodes were aluminum foils $(99.99 \%$ in purity), while the magnesium foil (99.99\% in purity) were served as both counter and reference electrodes.

The ethylmagnesium bromide in tetrahydrofuran $\left(1 \mathrm{~mol} \mathrm{~L}^{-1}\right.$ EtMgBr/THF) were obtained from the Acroseal company and the pure THF solution was purchased from the TCI company. All the electrodes were rinsed with pure THF $(99.99 \%)$ solutions and then dried at room temperature under vacuum for $24 \mathrm{~h}$ before testing. The scratched aluminum foils with a fresh surface were obtained by removing the surface oxide film with a knife.

The cyclic voltammetry (CV) tests were conducted from -0.5 to $0.5 \mathrm{~V}$ (vs. Mg RE) with a scanning rate of $5 \mathrm{mV} \mathrm{s}^{-1}$. The electrodeposition of magnesium was performed by using a galvanostatic method at a current density of $1.0 \mathrm{~mA} \mathrm{~cm}$. The time of the galvanostatic deposition is $30 \mathrm{~min}$. After electrodeposition, magnesium deposits were immediately rinsed with pure THF solutions for 3 times to remove the electrolytic solution.

The surface morphologies of aluminum foils were observed by a Hitachi S-4800 scanning electron microscopy (SEM). X-ray diffraction (XRD) patterns of magnesium deposits on the surface of aluminum foils were examined by a Rigaku D/max-2500 diffractometer with a $\mathrm{Cu} \mathrm{K \alpha}$ radiation in the $2 \theta$ range of $20^{\circ}-80^{\circ}$. The charge-discharge curves of aluminum foils were tested under different current densities $\left(0.5,1.0,1.5,2.0 \mathrm{~mA} \mathrm{~cm}{ }^{-2}\right)$ in $1 \mathrm{~mol} \mathrm{~L}^{-1} \mathrm{EtMgBr} /$ THF solution. The time of the galvanostatic charging is also $30 \mathrm{~min}$ and the cut-off voltage of discharging is $2.0 \mathrm{~V}$ (vs. Mg RE).

\section{Results and discussion}

Figure 1 displays the cyclic voltammograms of scratched aluminum foils in $1 \mathrm{~mol} \mathrm{~L}^{-1} \mathrm{EtMgCl} / \mathrm{THF}$ solution. It is seen that the 20th and 50th CV curves are essentially coincident with that of the 1st cycle. The magnesium is electrodeposited almost from $-0.18 \mathrm{~V}$ (vs. Mg RE) in each cycle. There is only one anodic peak and one cathodic peak in each CV curve, which represents the dissolution-deposition of magnesium in the electrolytic solution, respectively. This result means that the electrochemical reaction of magnesium deposition-dissolution on a scratched aluminum foil in $1 \mathrm{~mol} \mathrm{~L}^{-1} \mathrm{EtMgBr} / \mathrm{THF}$ solution is completely reversible.

Figure 2 shows the SEM images of aluminum foils before $\mathrm{CV}$ tests (Figure 2(a) and (b)) and after the 10th CV test in $1 \mathrm{~mol} \mathrm{~L}^{-1} \mathrm{EtMgBr} / \mathrm{THF}$ solution (Figure 2(c) and (d)), respectively. The surface morphology of aluminum foils before $\mathrm{CV}$ test is coarse and there are some sanding scratches 


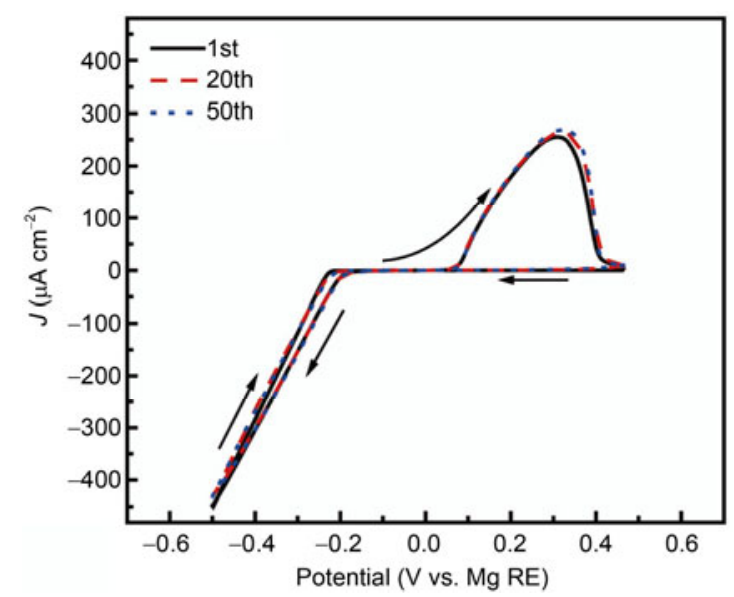

Figure 1 Cyclic voltammograms of magnesium deposition-dissolution on a scratched aluminum foil at 1st, 20th and 50th cycles in $1 \mathrm{~mol} \mathrm{~L}^{-1}$ EtMgBr/THF solution (scanning rate: $5 \mathrm{mV} \mathrm{s}^{-1}$ ).

on the surface of aluminum foils. The surface morphology of aluminum foils after the 10th CV test is essentially similar with that of aluminum foils before the CV test. There are no apparent traces of shedding caused by the alloying effect on the surface of aluminum foils after the 10th CV test. These results demonstrate that magnesium deposits could not form the $\mathrm{Mg}$-Al alloy on aluminum substrates during $\mathrm{CV}$ tests in $1 \mathrm{~mol} \mathrm{~L}^{-1} \mathrm{EtMgBr} / \mathrm{THF}$ solution.

Figure 3 shows the SEM images of magnesium deposits after $30 \mathrm{~min}$ of the galvanostatic electrodeposition on a scratched aluminum foil. As shown in Figure 3(a), the obtained magnesium deposits are composed of many scattered grains with a round shape and do not show a dendritic morphology. Furthermore, the magnified image (Figure 3(b)) shows that these magnesium grains have a uniform size approximately $30 \mu \mathrm{m}$ and each grain shows a clear edge reflecting the hexagonal structure of magnesium. This result suggests that the magnesium deposits could not form a dendritic morphology during the process of deposition-dissolution in $1 \mathrm{~mol} \mathrm{~L}^{-1} \mathrm{EtMgBr} / \mathrm{THF}$ solution, which is consistent with the result of magnesium elecrtrodeposition on a polished platinum substrate in $2 \mathrm{~mol} \mathrm{~L}^{-1} \mathrm{EtMgCl} / \mathrm{THF}$ solution [8].

Figure 4 displays the XRD patterns of aluminum foils before the $\mathrm{CV}$ test and after the 10 th $\mathrm{CV}$ test in $1 \mathrm{~mol} \mathrm{~L}^{-1}$ EtMgBr/THF solution. The XRD pattern before the CV test (Figure 4(a)) is corresponding to that of the pure aluminum (JCPDS card No. 89-4037), while the XRD pattern after the 10th CV test (Figure 4(b)) is assigned to the pure magnesium (JCPDS card No. 89-4244) except for peaks of aluminum substrates. The diffraction peaks of $\mathrm{Mg}$ - $\mathrm{Al}$ alloy phase cannot be found in Figure 4(b), which further indicates that the $\mathrm{Mg}-\mathrm{Al}$ alloy as the magnesium deposits could not form on aluminum substrates during $\mathrm{CV}$ processes in $1 \mathrm{~mol} \mathrm{~L}^{-1}$ $\mathrm{EtMgBr} / \mathrm{THF}$ solution.

Figure 5 shows the charge-discharge curves of aluminum foils under different current densities (0.5, 1.0, 1.5, 2.0 $\mathrm{mA} \mathrm{cm}{ }^{-2}$ ) in $1 \mathrm{~mol} \mathrm{~L}^{-1} \mathrm{EtMgBr} / \mathrm{THF}$ solution. The potential of the magnesium deposition gradually shifts to the negative direction with the increasing of current densities during the charging process. All potentials of the magnesium deposition under different current densities are essentially stable,
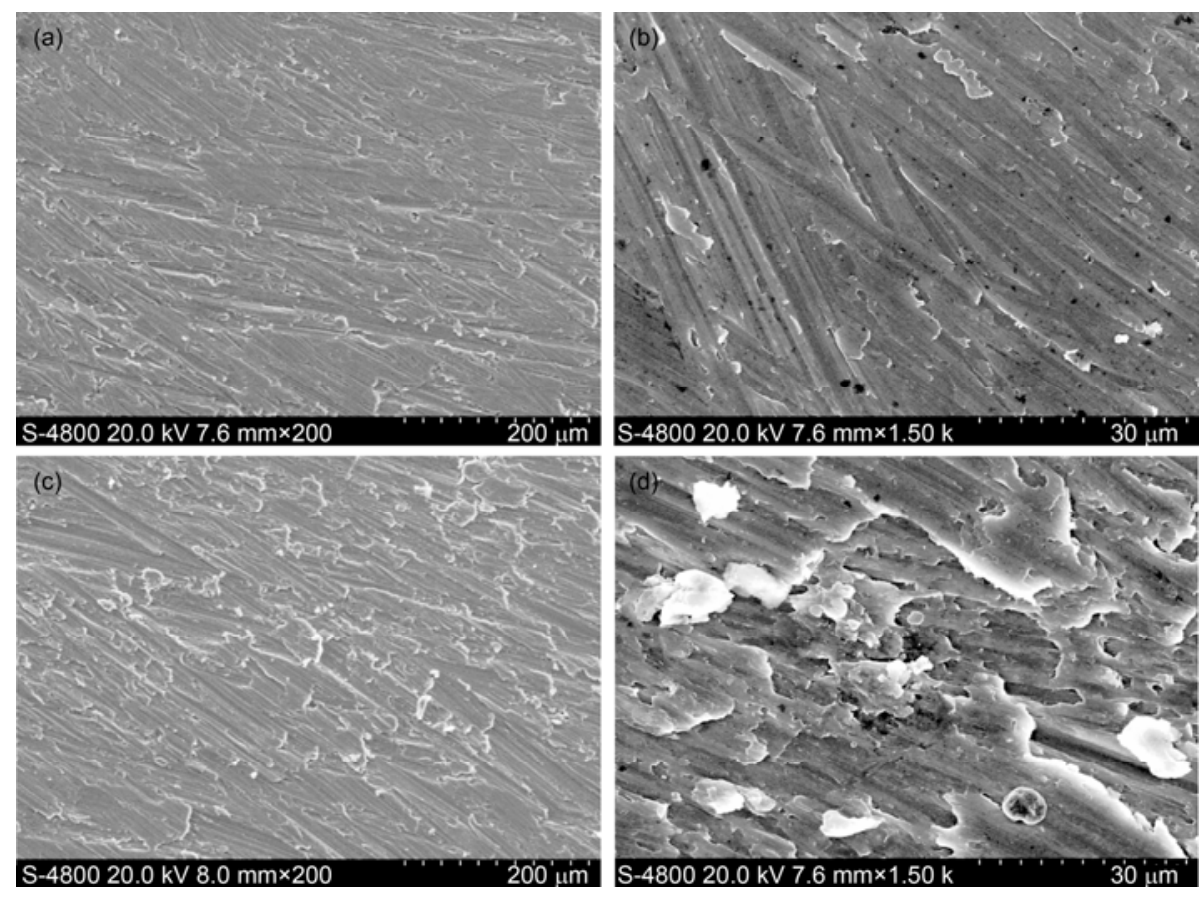

Figure 2 SEM images of aluminum foils before the CV test ((a), (b)) and after the 10th CV test ((c), (d)) in $1 \mathrm{~mol} \mathrm{~L}{ }^{-1}$ EtMgBr/THF solution. 

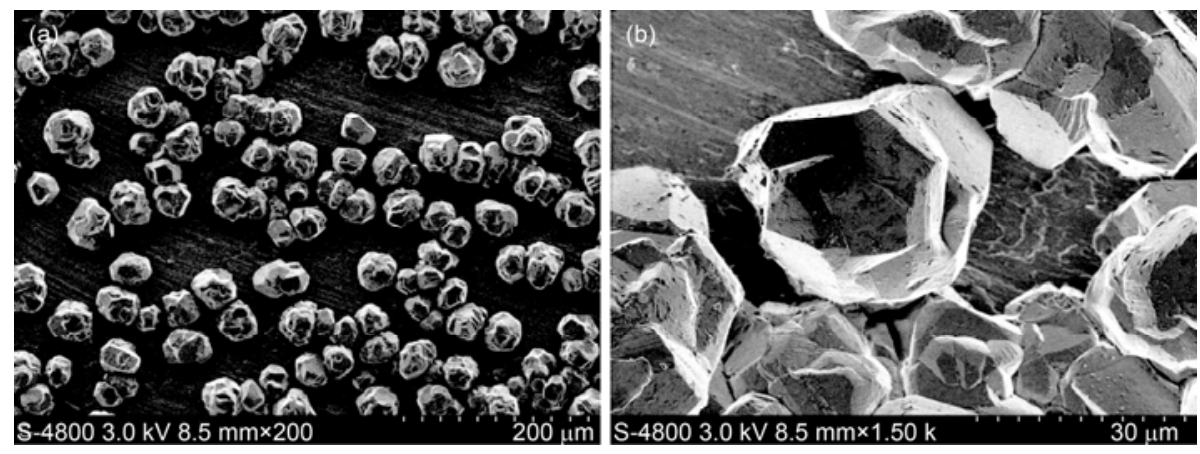

Figure 3 SEM images of magnesium deposits on a scratched aluminum foil after $30 \mathrm{~min}$ of the galvanostatic electrodeposition.

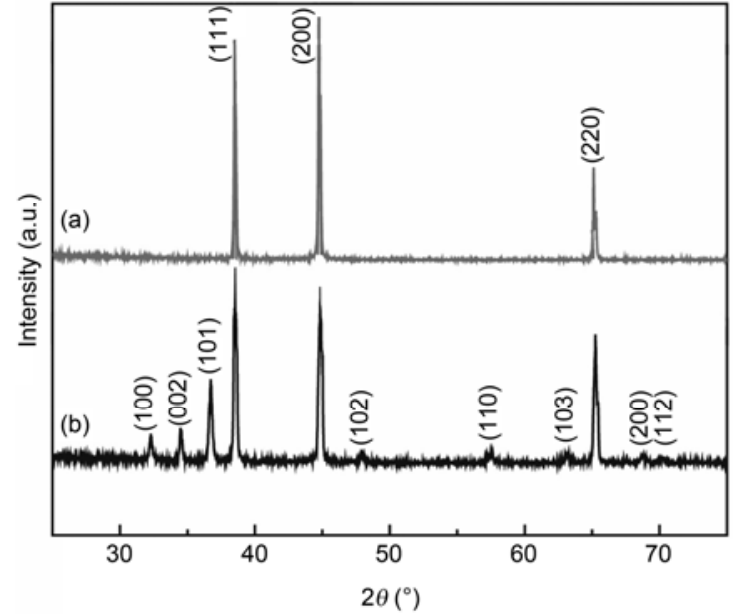

Figure 4 XRD patterns of aluminum foils before the CV test and after the10th $\mathrm{CV}$ test in $1 \mathrm{~mol} \mathrm{~L}^{-1} \mathrm{EtMgBr} / \mathrm{THF}$ solution. (a) Before the $\mathrm{CV}$ test, (b) after the 10th CV test.



Figure 5 Charge-discharge curves of aluminum foils under different current densities in $1 \mathrm{~mol} \mathrm{~L}^{-1} \mathrm{EtMgBr} / \mathrm{THF}$ solution.

which indicates that no magnesium dendrite has generated on the surface of aluminum foils during the charging process. Furthermore, the potential of the magnesium dissolution gradually shifts to the positive direction with the increasing of current densities during the discharging process. All potentials of the magnesium dissolution under different current densities are also steady in the initial stage of discharging processes. However, these potentials of the magnesium dissolution under different current densities increase abruptly at the end of discharging processes due to the depletion of magnesium deposits.

Figure 6 demonstrates the curves of the charge-discharge efficiency (Coulombic efficiency) during cycling tests for aluminum foils under different current densities in $1 \mathrm{~mol} \mathrm{~L}^{-1}$ EtMgBr/THF solution. The Coulombic efficiency is calculated according to the ratio of the charging amount of magnesium dissolution to that of magnesium deposition. It is evident that the Coulomb efficiency decreases with the increasing of current densities. The capacity loss due to magnesium dissolution is mainly found during the initial 10 cycles under different current densities. However, the Coulomb efficiency shows an obviously stable value after the 15 th cycle under different current densities. The stable values of Coulomb efficiency are about $93 \%, 86 \%, 70 \%$ and $65 \%$ under the current densities of $0.5,1.0,1.5$, and $2.0 \mathrm{~mA} \mathrm{~cm}^{-2}$, respectively. These results are superior to that of magnesium deposition-dissolution on aluminum substrates in the $\mathrm{C}_{4} \mathrm{H}_{8} \mathrm{NMgX} / \mathrm{THF}(\mathrm{X}=\mathrm{Br}, \mathrm{Cl})$ solution. This is because the process of magnesium deposition-dissolution is accompanied

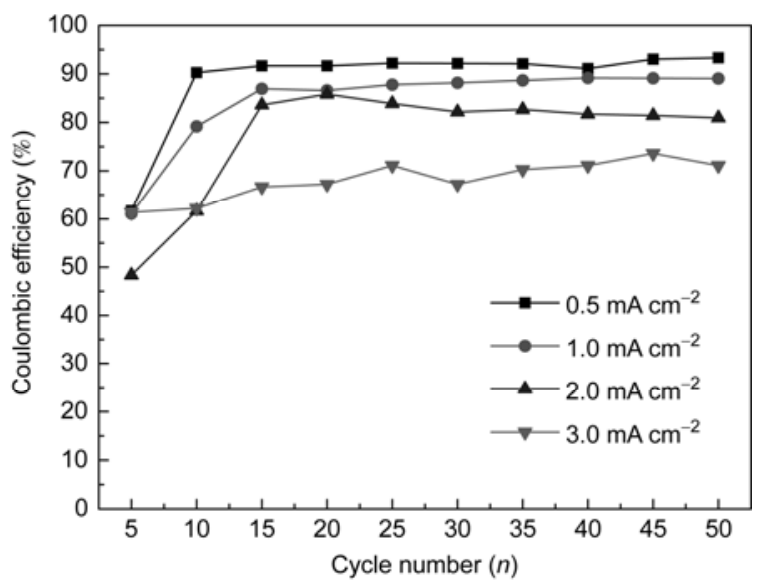

Figure 6 Dependence of the Coulombic efficiency on the cyclic number for aluminum foils under different current densities in $1 \mathrm{~mol} \mathrm{~L}^{-1} \mathrm{EtMgBr} /$ THF solution. 
by different adhesion and cohesion of the specific adsorbed species on the surface of aluminum substrates, which may influence the nucleation process of magnesium [33]. Therefore, the Coulombic efficiency of magnesium depositiondissolution on the surface of aluminum substrates in different electrolytic solutions is obviously different.

\section{Conclusion}

The electrochemical deposition-dissolution behavior of magnesium on scratched aluminum foils in $1 \mathrm{~mol} \mathrm{~L}^{-1} \mathrm{EtMgBr} /$ THF solution was studied by CV, SEM, XRD and chargedischarge tests. The results show that the obtained magnesium deposits have not exhibited a dendritic morphology and the $\mathrm{Mg}-\mathrm{Al}$ alloy has not been found in the obtained magnesium deposits. The aluminum foils have a good cyclic performance in $1 \mathrm{~mol} \mathrm{~L}^{-1} \mathrm{EtMgBr} / \mathrm{THF}$ solution. These results provide a prospect that the aluminum could be used as a candidate material for the negative current collector of rechargeable magnesium batteries.

This work was supported by the National Natural Science Foundation of China (20973124) and the Open Project of Key Laboratory of Advanced Energy Materials Chemistry (Nankai University) (KLAEMC-OP201101).

1 Armand M, Tarascon J M. Building better batteries. Nature, 2008, 451: 652-657

2 Goodenough J B, Kin Y. Challenges for rechargeable batteries. J Power Sources, 2011, 196: 6688-6694

3 Arbizzani C, Gabrielli G, Mastragostino M. Thermal stability and flammability of electrolyte for lithium-ion batteries. J Power Sources, 2011, 196: 4801-4805

4 Zaghib K, Dontigny M, Guerfi A, et al. Safe and fast-charging Li-ion battery with long shelf life for power applications. J Power Sources, 2011, 196: 3949-3954

5 Levi E, Gofer Y, Aurbach D. On the way to rechargeable Mg batteries: The challenge of new cathode materials. Chem Mater, 2010, 22: 860-868

$6 \mathrm{Li} \mathrm{W} \mathrm{Y,} \mathrm{Li} \mathrm{C} \mathrm{S,} \mathrm{Zhou} \mathrm{C} \mathrm{Y,} \mathrm{et} \mathrm{al.} \mathrm{Metallic} \mathrm{magnesium} \mathrm{nano/}$ mesoscale structures: Their shape-controlled preparation and $\mathrm{Mg} / \mathrm{Air}$ battery applications. Angew Chem Int Ed, 2006, 45: 6009-6012

$7 \mathrm{Li}$ Y, Nuli Y N, Yang J, et al. $\mathrm{MgFeSiO}_{4}$ prepared via a molten salt method as a new cathode material for rechargeable magnesium batteries. Chin Sci Bull, 2011, 56: 386-390

8 Matsui M. Study on electrochemically deposited Mg metal. J Power Sources, 2011, 196: 7048-7055

9 Liebenow C. Reversibility of electrochemical magnesium deposition from Grignard solutions. J Appl Electrochem, 1997, 27: 221-225

10 Aurbach D, Lu Z, Schechter A, et al. Prototype systems for rechargeable magnesium batteries. Nature, 2000, 407: 724-727

11 Aurbach D, Schechter A, Moshkovich M, et al. On the mechanism of reversible magnesium deposition processes. J Electrochem Soc, 2001, 148: A1004-A1014

12 Aurbach D, Cohen Y, Moshkovich M. The study of reversible magnesium deposition by in situ scanning tunneling microscopy. Elec- trochem Solid-State Lett, 2001, 4: A113-A116

13 Aurbach D, Gizbar H, Schechter A, et al. Electrolyte solutions for rechargeable magnesium batteries based on organomagnesium chloroaluminate complexes. J Electrochem Soc, 2002, 149: A115-A121

14 Aurbach D, Schechter A, Moshkovich M, et al. Electrolyte solutions with a wide electrochemical window for rechargeable magnesium batteries. J Electrochem Soc, 2008, 155: A103-A109

15 Nuli Y N, Yang J, Wu R. Reversible deposition and dissolution of magnesium from $\mathrm{BMIMBF}_{4}$ ionic liquid. Electrochem Commun, 2005, 7: 1105-1110

16 Nuli Y N, Yang J, Wang J L, et al. Electrochemical magnesium deposition and dissolution with high efficiency in ionic liquid. Electrochem Solid-State Lett, 2005, 8: C166-C169

17 Wang P, Nuli Y N, Yang J, et al. Mixed ionic liquids as electrolyte for reversible deposition and dissolution of magnesium. Surf Coat Technol, 2006, 201: 3783-3787

18 Gummow R J, He Y H. Morphology and preferred orientation of pulse electrodeposited magnesium. J Electrochem Soc, 2010, 157: E45-E49

19 Zhao Q S, Nuli Y N, Guo Y S, et al. Reversibility of electrochemical magnesium deposition from tetrahydrofuran solutions containing pyrrolidinyl magnesium halide. Electrochim Acta, 2011, 47: 65306535

20 Kakibe K, Yoshimoto N, Egashira M, et al. Optimization of cation structure of imidazolium-based ionic liquids as ionic solvents for rechargeable magnesium batteries. Electrochem Commun, 2010, 7: 1630-1633

21 Yoshimoto N, Matsumoto M, Egashira M, et al. Mixed electrolyte consisting of ethylmagnesiumbromide with ionic liquid for rechargeable magnesium electrode. J Power Sources, 2010, 195: 2096-2098

22 Kakibe K, Hishii J Y, Yoshimoto N, et al. Binary ionic liquid electrolytes containing organo-magnesium complex for rechargeable magnesium batteries. J Power Sources, 2012, 203: 195-200

23 Behl W K, Plichta E J. Stability of aluminum substrates in lithiumion battery electrolytes. J Power Sources, 1998, 72: 132-135

24 Myung S T, Natsui H, Sun Y K, et al. Electrochemical behavior of Al in a non-aqueous alkyl carbonate solution containing LiBOB salt. J Power Sources, 2010, 195: 8297-8301

25 Morita M, Shibata T, Yoshimoto N, et al. Anodic behavior of aluminum in organic solutions with different electrolytic salts for lithium ion batteries. Electrochim Acta, 2002, 47: 2787-2793

26 Song S W, Richardson T J, Zhuang G V, et al. Effect on aluminum corrosion of $\mathrm{LiBF}_{4}$ addition into lithium imide electrolyte: A study using the EQCM. Electrochim Acta, 2004, 49: 1483-1490

27 Li Y X, Fedkiw P S. Effect of gel electrolytes containing silica nanoparticles on aluminum corrosion. Electrochim Acta, 2007, 52: 24712477

28 Xie H, Tang Z Y, Li Z Y, et al. Aluminum corrosion behavior of LiBOB in composite polymer electrolyte for Li-polymer batteries. Electrochem Solid-State Lett, 2008, 11: C19-C22

29 Peng C X, Yang L, Zhang Z X, et al. Anodic behavior of Al current collector in 1-alkyl-3-methylimidazolium bis[(trifluoromethyl)sulfonyl] amide ionic liquid electrolytes. J Power Sources, 2007, 173: 510-517

30 Kawakita J, Kobayashi K. Anodic oxidation behaviour of aluminium in propylene carbonate. J Power Sources, 2000, 90: 182-187

31 Thackeray M M, Vaughey J T, Johnson C S, et al. Structural considerations of intermetallic electrodes for lithium batteries. J Power Sources, 2004, 113: 124-130

32 Hamon Y, Brousse T, Jousse F, et al. Alumium negative electrode in lithium ion batteries. J Power Sources, 2001, 97-98: 185-187

33 Aurbach D, Turgeman R, Chusid O, et al. Spectroelectrochemical studies of magnesium deposition by in situ FTIR spectroscopy. Electrochem Commun, 2001, 3: 252-261

Open Access This article is distributed under the terms of the Creative Commons Attribution License which permits any use, distribution, and reproduction in any medium, provided the original author(s) and source are credited. 